Ophthalmologica 1959;138:321

\title{
Hans Goldmann zum 60. Geburtstag
}

Am 21. November feiert Professor Hans Goldmann in Bern seinen 60. Geburtstag.

Die Ophthalmologen der ganzen Welt sind dem Jubilar zu großem Dank verpflichtet für alles, was er für unser Fach geleí-stet hat.

Seínem Drang nach Genauígkeit, seiner technischen Begabung verdanken wir verschíedene Apparate und Instrumente. die dem Facharzt nahezu unentbehrlich sind. Es sínd das wesentliche Änderungen und Ergänzungen, die eine Vereinfachung der Unter-suchungen und eine erhöhte Exaktheii der Messungen erlauben. Genannt seien nur: Die Kammerwinkeluntersuchungen in alien Richtungen, die Untersuchung des Augenhintergrundes bis gegen die Peripherie und die Applanationstonometrie. Wesentliche Ver-besserungen bilden auch das Projektionsperimeter und das Adap-iometer sowie die Fremdkörperlokalisation. Wichtíge klinische Untersuchung en bezüglich des Glaukoms und seiner Genese verdanken wir ebenfalls Hans Goldmann.

Es würde zu weit führen, die zahlreichen Arbeiten, die auch sonst auf verschiedenen Gebieten unser Wissen erweitert haben, im einzelnen anzuführen. Sie alle tragen den Stempel: Wissenschaftliche Exaktheit und Zuverlässigkeit.

D. Den Glückwünschen die dem Gefeierten dargebracht werden möchte sich auch unsere Zeitschrift aufs herzlichste anschließen und íhm noch viel Erfolg für die Zukunft wünschen.

Redaktion und Verlag der Ophthalmologica 